\title{
Sex- and Age-Dependent Changes in Polysensitization to Common Aeroallergens Over 20 Years
}

\author{
Caroline Beutner' \\ Susann Forkel' \\ Sidhi Gupta' \\ Thomas Fuchs' \\ Michael P Schön (D) ${ }^{1,2}$ \\ Johannes Geier ${ }^{2,3}$ \\ Timo Buhl (1) ${ }^{1,2}$ \\ 'Department of Dermatology, \\ Venereology and Allergology, University \\ Medical Center Göttingen, Göttingen, \\ Germany; ${ }^{2}$ Lower Saxony Institute of \\ Occupational Dermatology, University \\ Medical Center Göttingen, Göttingen, \\ Germany; ${ }^{3}$ Information Network of \\ Departments of Dermatology (IVDK), \\ University of Göttingen, Göttingen, \\ Germany
}

This article was published in the following Dove Press journal: Journal of Asthma and Allergy

Introduction: The prevalence of airway allergies in Europe has increased from $23 \%$ to $31 \%$ in recent years. Polysensitization is associated with the development and severity of relevant allergies, particularly allergic asthma.

Objective: We investigated age- and sex-dependent monosensitization and polysensitization profiles as well as patterns of sensitization using skin prick test (SPT) reactivity to the most common aeroallergens.

Patients and Methods: From 1998 to 2017, SPTs were retrospectively analyzed in 2886 symptomatic patients, referred to the University Medical Center Göttingen, located in central Germany. The major aeroallergen groups early flowering tree pollen, grass pollen, and house dust mites were evaluated in this study. Wheal diameters $\geq 2 \mathrm{~mm}$ were considered positive during the entire study period.

Results: Polysensitization to the most common aeroallergen groups increased significantly over 20 years. Boys and young men displayed the most remarkable rise in total sensitization rates in our study group over time.

Discussion: Our patient-based study demonstrates a continuing increase in polysensitization rates over the last 20 years, with boys and young men being most frequently affected. Our data-without being a population-based study — suggest a scenario with climbing rates of allergic rhinitis and asthma.

Keywords: aeroallergens, polysensitization, sensitization pattern, skin prick test

\section{Introduction}

The prevalence of airway allergies in Europe has increased from 23\% to 31\% in recent years. ${ }^{1}$ In Germany, high lifetime prevalences of $8.6 \%$ for asthma and $14.8 \%$ for allergic rhinitis were reported in $2013 .^{2}$ Polysensitization is associated with the development and severity of allergies, particularly allergic asthma. ${ }^{3,4}$ We investigated age- and sex-dependent mono- and polysensitization profiles using skin prick test (SPT) reactivity to the most common aeroallergens. In addition, patterns of sensitization against the structurally different allergens of the major aeroallergen groups early flowering tree pollen, grass pollen, and house dust mites (HDM) were analyzed in a large German study group during the last 20 years. Different medical aspects of this study population, together with regional pollen counts and SPT reactivity, have been published previously. ${ }^{5}$
Correspondence: Caroline Beutner Department of Dermatology, Venereology and Allergology, University Medical Center Göttingen, Georg August University, Robert Koch-Str. 40, Göttingen D-37075, Germany Tel +4955 I 3966402

Email caroline.beutner@med.unigoettingen.de 


\section{Patients and Methods}

From 1998 to 2017, SPTs were retrospectively analyzed in 2886 symptomatic patients at the University Medical Center Göttingen (tertiary referral center), located in central Germany. This study was reviewed and approved by the local ethics committee at the University Medical Center Göttingen (3/8/17). The patients tested in the period from 1998 to 2007 (decade I; 1672 patients) were compared with those tested in the period from 2008 to 2017 (decade II; 1214 patients) (equal age distribution of patients in both decades). Our analysis included all symptomatic patients with airway allergies at our center who underwent SPTs with aeroallergens. Each patient is counted only once, although 14 patients $(0.5 \%$ of 2886$)$ have had more than one SPT with the aeroallergens in the course of these 20 years. In these 14 patients, the last consultation was selected for data analysis. Total sensitization rates were based on SPTs with birch, alder, hazel, timothy, rye, and the HDM Dermatophagoides pteronyssinus and D. farinae. SPTs were performed according to current guidelines by only three different nurses over the study period of 20 years, ruling out significant bias caused by different evaluators. Wheal diameters $\geq 2 \mathrm{~mm}$ were considered positive during the entire study period until 2017. Different from today's standard of wheal diameters $\geq 3 \mathrm{~mm}$ for positive reactions, reactions $\geq 2 \mathrm{~mm}$ were regarded as positive in the late 1990s, especially for epidemiologic studies. ${ }^{6}$ Commercial SPT extracts were equally obtained from ALK Abelló (ALK-prick SQ, Hamburg, Germany) and Allergopharma (Reinbek, Germany). All SPT extracts of these common allergens were approved by the national authorities in the 1980s and remain valid today. Thus, manufacturing and standardization procedures, as well as quality management for batchto-batch consistency, were unchanged during the study period.

\section{Results}

One-third of our study group of 2886 patients were male (33.7\%) and two-thirds were female (66.3\%), and those proportions did not change during the 20 years. The SPT results were grouped into early flowering trees (birch, alder, hazel), grass (timothy, rye), and HDM (D. pteronyssinus, D. farinae). The reason for this grouping was the close relationship and thus broad co-reactivity in SPTs between birch, alder, and hazel, as well as timothy and rye, and D. pteronyssinus and $D$. farinae. Monosensitization was diagnosed if the SPT was positive to one allergen group only (positive for at least one allergen in the group). Polysensitization was diagnosed if the patient responded to two or three allergen groups (positive for at least one allergen in two or more groups). Almost twothirds of patients $(65.7 \%)$ were sensitized to at least one allergen, and another two-thirds of the sensitized showed polysensitization versus one-third monosensitization (45.1\% versus $20.6 \%$ ) (Table 1). Of note, polysensitization was more frequent in male than in female patients $(50.9 \%$ vs $42.1 \%)$.

In all age groups, the rate of sensitization to allergens from the three allergen groups increased equally (Figure 1). During decade I, the highest total prevalence of sensitization was found in children and adolescents (11-20 years old). Interestingly, we identified a shift in peak rates for sensitization towards young adults (21-30 years) in decade II (Figure 1). Statistical analysis revealed significant overall changes between the two decades for grass pollen $(\mathrm{p}=0.019)$ and house dust mites $(\mathrm{p}=0.015)$, while the identical trend for increasing sensitization to tree pollen did not reach significance $(\mathrm{p}=0.173)$. The proportion of nonsensitized patients in the total study population decreased from $39.7 \%$ to $27.0 \%$, mainly in favor of an increase of polysensitized patients, which increased significantly from $40.1 \%$ to $51.9 \%$ (Table 2). Monosensitization remained largely unchanged in both decades.

Dissecting the sensitization profiles for patient ages (Figure 2), the highest total polysensitization rates were found for children and younger adults. The most pronounced decrease in nonsensitization was found among the elderly, although they remained the largest group without sensitization. Regarding sex-related profiles, we observed a remarkable increase from $65.2 \%$ to $79.9 \%$ in total sensitization rate in men (Figure 2). Following the same trend but at a lower level, sensitization rates in women climbed from $57.8 \%$ to $69.6 \%$ over time. Boys and young men up to 30 years of age had the highest total polysensitization rates (decade I: 51.7-62.5\%; decade II: $60.9-85.3 \%$ ). Female patients also reached their peak in polysensitization in these age groups but again at a lower level (decade I: 46.4-54.3\%; decade II: 53.9-58.9\%). Of note, the age peak of polysensitized patients shifted for both sexes from the 11-20 year group to the 21-30 year group during the study period. In decade I, statistical comparison of polysensitized male and female patients revealed no significant differences in all age groups by proportionality test. However in decade II, sex-related polysensitization rates were significantly different for the 11-20-year-olds 
Table I Characteristics of the Study Group (1998-2017)

\begin{tabular}{|c|c|c|c|}
\hline & \multicolumn{3}{|l|}{$1998-2017$} \\
\hline & Total [\%] & Male [\%] & Female [\%] \\
\hline Total study group & $2886[100.00]$ & $973[100.00]$ & $1913[100.00]$ \\
\hline Non-Sensitization & 991 [34.34] & 280 [28.78] & 711 [31.17] \\
\hline Sensitization & $1895[65.66]$ & 693 [71.22] & $1202[62.83]$ \\
\hline Monosensitization (Sensitization to I allergen group only) & $595[20.62]$ & $198[20.35]$ & 397 [20.75] \\
\hline Polysensitization (Sensitization to $\geq 2$ allergen groups) & 1300 [45.05] & $495[50.87]$ & $805[42.08]$ \\
\hline
\end{tabular}

Notes: All patients underwent skin prick tests (SPTs) with the major aeroallergen-groups early flowering trees (birch, alder, hazel), grass (timothy, rye) and house dust mites (D. pteronyssinus, D. farinae). Sensitized patients were subdivided into monosensitization (SPT positive to one allergen-group only) and polysensitization (SPT positive to $\geq 2$ allergen groups).

( $\mathrm{p}=0.046), 21-30$-year-olds $(\mathrm{p}<0.001)$, and 61-70-yearolds $(\mathrm{p}=0.039)$. The other age groups did not reveal significant differences. Interestingly, the proportion of monosensitized individuals remained quite low and unchanged over time (male patients: $19.6-20.9 \%$, female patients: $19.9-22.0 \%)$. Thus, patients with polysensitization
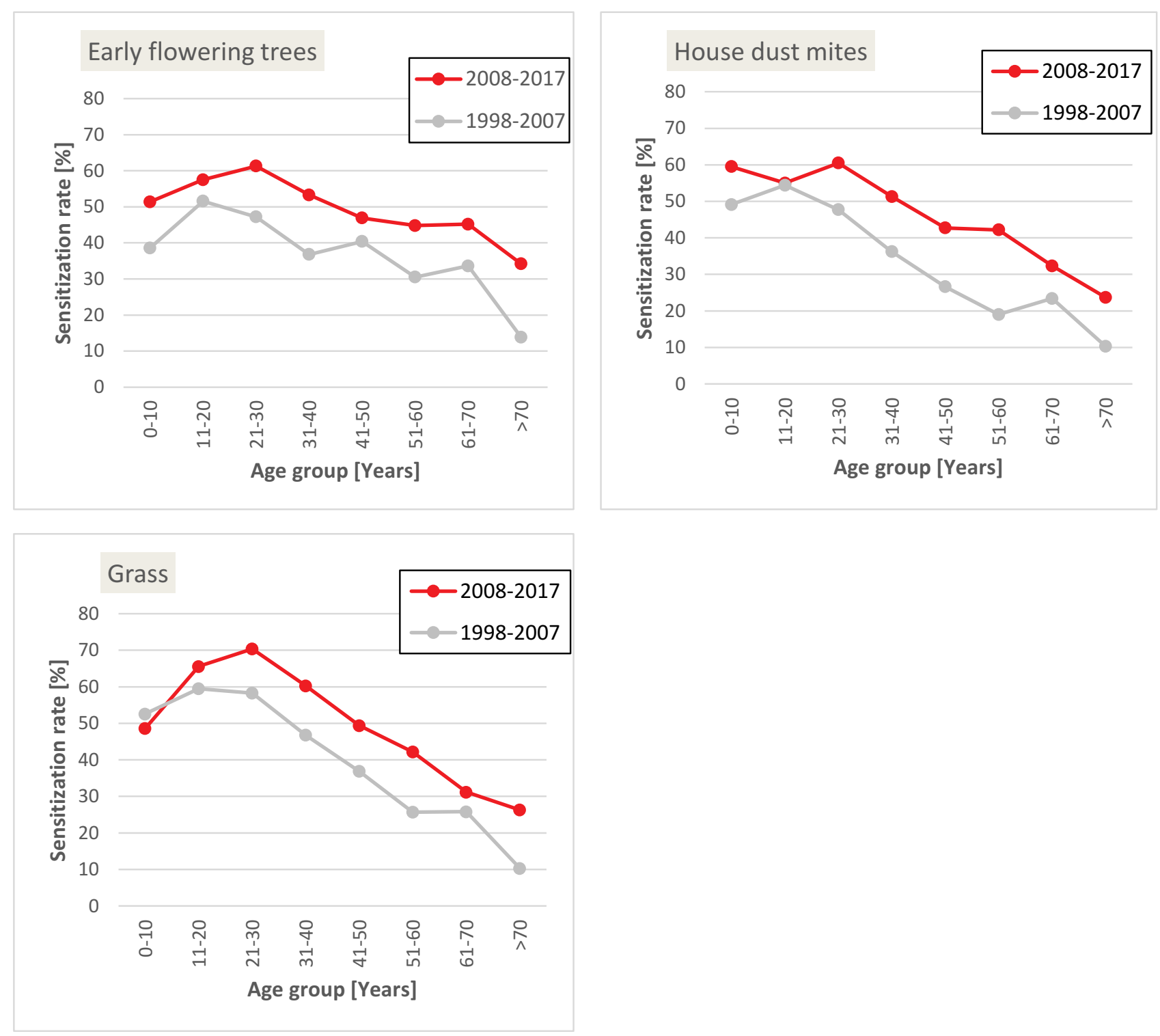

Figure I Positive skin prick test (SPT) rates for the different aeroallergen groups (early flowering trees, grass, and house dust mites) increase from decade I (I998-2007; $\mathrm{n}=1672$ patients) to decade II (2008-20I7; $\mathrm{n}=1214$ patients). 
Table 2 Distribution of Sensitization Patterns Over Time

\begin{tabular}{|l|l|l|l|l|l|}
\hline \multicolumn{2}{|l|}{ Allergen Groups } & \multicolumn{2}{l|}{ Patients } & \\
\hline \multirow{2}{*}{ Tree } & \multirow{2}{*}{ Grass } & HDM & \multicolumn{2}{l|}{$\begin{array}{l}\text { Among the Total Study Population (And Among the Subgroup with } \geq \text { I Positive SPT } \\
\text { only) }\end{array}$} & Significance (p-values) \\
\cline { 3 - 6 } & & & $1998-2007$ & $2008-2017$ & \\
\hline+ & - & - & $6.0 \%(10.0 \%)$ & $5.5 \%(7.6 \%)$ & 0.555 \\
- & + & - & $6.3 \%(9.9 \%)$ & $7.3 \%(9.9 \%)$ & 0.336 \\
- & - & + & $7.8 \%(12.0 \%)$ & $8.4 \%(11.5 \%)$ & 0.581 \\
+ & + & - & $12.1 \%(20.0 \%)$ & $11.7 \%(16.0 \%)$ & 0.982 \\
+ & - & + & $2.4 \%(4.0 \%)$ & $4.7 \%(6.4 \%)$ & $<0.001$ \\
- & + & + & $6.0 \%(10.0 \%)$ & $5.8 \%(7.9 \%)$ & 0.758 \\
+ & + & + & $19.6 \%(32.5 \%)$ & $29.7 \%(40.6 \%)$ & $<0.001$ \\
- & - & - & $39.7 \%($ n.a.) & $27.0 \%($ (n.a.) & $<0.001$ \\
\hline
\end{tabular}

Notes: $(+)$ indicates positive SPTs to the allergen group, and (-) indicates negative SPTs to the allergen group. All patients were tested for the three major aeroallergen groups: tree pollen, grass pollen, and house dust mites (HDM). 1998-2007: $n=1672$ patients; 2008-2017: $n=1214$ patients. Significance was tested by proportionality test.

Abbreviations: $\mathrm{n}$. a, not applicable; SPT, skin prick test.

clearly accounted for the strong increase in sensitization rates, with significant differences between male and female children, adolescents and young adults.
Of the three allergen groups, the highest monosensitization rates were observed for HDM (11.5-12.0\%, Table 2). The combination of tree and grass pollen sensitization was
Nonsensitization

MALE patients [\%]

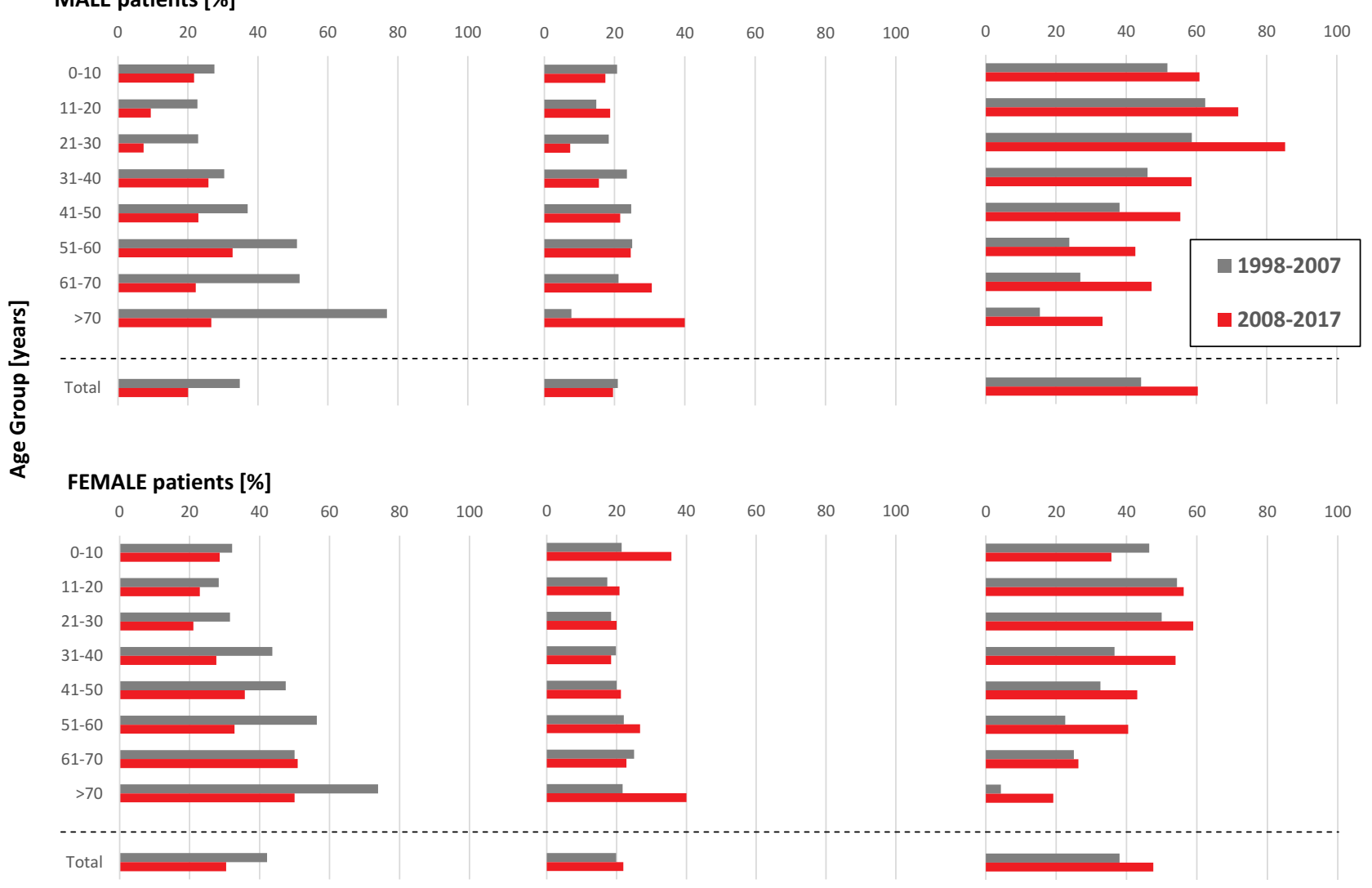

Figure 2 Skin prick tests were categorized into the three major aeroallergen groups: tree pollen, grass pollen, and house dust mites. Graphs display results from $1998-2007$ (grey bars) and 2008-2017 (red bars). Sensitized patients were subdivided into monosensitization (positive to one allergen group only) and polysensitization (positive to two or three allergen groups). Upper row: male patients $(n=973)$, lower row: female patients $(n=1913)$. 
highest among polysensitized individuals with two out of three positively tested allergen groups (16.0-20.0\%), whereas polysensitization rates to all three allergen groups tested were always highest (32.5-40.6\%). The highly significant increase in polysensitization to all three allergen groups mostly accounted for the increase in total polysensitization rates over all age and sex groups during the study period.

\section{Discussion}

Our patient-based study demonstrates a continuing increase in polysensitization rates over the last 20 years, with boys and young men being most frequently affected. To the best of our knowledge, no current trends are available for sensitization profiles in German patients over the last 20 years. Our findings are consistent with a German population-based study from 2008 to 2011, which also reported that the highest sensitization rates were in young adults. ${ }^{7}$ Identical time trends were obtained in the United States National Health and Nutrition Examination Survey (NHANES) II and III studies, which reported increasing rye sensitization rates for all age groups over time, with current peaks in the 20-29 year group. ${ }^{8}$ In addition, we recently published results on increasing positive SPTs in weed allergic patients from our region during the last 20 years. ${ }^{9}$ Of note, we expected higher total sensitization rates in our current study than in populationbased studies because our study population consisted of referred patients with suspected airway allergies and our cut-off $\geq 2 \mathrm{~mm}$ for positive SPTs was lower than in most current studies.

Because sensitization to aeroallergens during childhood is largely persistent and associated with polysensitization, early sensitization patterns are also strongly associated with manifestation of the asthma-rhinitis multimorbid phenotype. ${ }^{10,11}$ Therefore, our data-without being a population-based study — suggest a scenario with climbing rates of allergic rhinitis and asthma. Limitations of our study include the single-center setting of referred patients to a university hospital and the cut-off level for wheal diameters of $\geq 2 \mathrm{~mm}$ for positive SPTs, although this was recommended in the late 1990s for epidemiological studies. If our finding of increasing sensitization to different allergen groups also correlates with clinical findings, we will need to revisit the question on the use of simultaneous immunotherapies with multiple allergens, which remains a fiercely debated issue in different areas of the world. $^{12}$

\section{Data Sharing Statement}

Data and materials of this study are available from CB on request.

\section{Ethics Approval and Consent to Participate}

This retrospective study was reviewed and approved by the local ethics committee at the University Medical Centre Göttingen (3/8/17). Data analysis was performed anonymized thus no individual patients consent was required. This study was performed in accordance with the principles stated in the Declaration of Helsinki.

\section{Consent for Publication}

All authors reviewed the final manuscript version and consented to its submission.

\section{Author Contributions}

All authors made substantial contributions to conception and design, acquisition of data, or analysis and interpretation of data; took part in drafting the article or revising it critically for important intellectual content; agreed to submit to the current journal; gave final approval of the version to be published; and agree to be accountable for all aspects of the work.

\section{Funding}

There is no funding to report.

\section{Disclosure}

None of the authors have a conflict of interest in relation to this work. The authors have no ethical conflicts to disclose.

\section{References}

1. Zuberbier T, Lotvall J, Simoens S, Subramanian SV, Church MK. Economic burden of inadequate management of allergic diseases in the European Union: a GA(2) LEN review. Allergy. 2014;69:1275-1279. doi:10.1111/all.12470

2. Langen U, Schmitz R, Steppuhn H. [Prevalence of allergic diseases in Germany: results of the German Health Interview and Examination Survey for Adults (DEGS1)]. Bundesgesundheitsblatt Gesundheitsforschung Gesundheitsschutz. 2013;56:698-706. doi:10.1007/ s00103-012-1652-7. German.

3. Demoly P, Passalacqua G, Pfaar O, Sastre J, Wahn U. Management of the polyallergic patient with allergy immunotherapy: a practice-based approach. Allergy Asthma Clin Immunol. 2016;12:2. doi:10.1186/ s13223-015-0109-6

4. Schoos AM, Jelding-Dannemand E, Stokholm J, Bonnelykke K, Bisgaard H, Chawes BL. Single and multiple time-point allergic sensitization during childhood and risk of asthma by age 13. Pediatr Allergy Immunol. 2019;30:716-723. doi:10.1111/pai.13109 
5. Beutner C, Werchan B, Forkel S, et al. Sensitization rates to common inhalant allergens increase and change patterns over the last 20 years in Germany. J Dtsch Dermatol Ges. 2020. doi:10.1111/ddg.14312

6. Bousquet J, Heinzerling L, Bachert C, et al. Practical guide to skin prick tests in allergy to aeroallergens. Allergy. 2012;67:18-24. doi:10.1111/j.1398-9995.2011.02728.x

7. Haftenberger M, Laussmann D, Ellert U, et al. [Prevalence of sensitisation to aeraoallergens and food allergens: results of the German Health Interview and Examination Survey for Adults (DEGS1)]. Bundesgesundheitsblatt Gesundheitsforschung Gesundheitsschutz. 2013;56:687-697. doi:10.1007/s00103-012-1658-1. German.

8. Arbes SJ, Gergen PJ, Elliott L, Zeldin DC. Prevalences of positive skin test responses to 10 common allergens in the US population: results from the third National Health and Nutrition Examination Survey. J Allergy Clin Immunol. 2005;116:377-383. doi:10.1016/j. jaci.2005.05.017
9. Forkel S, Beutner C, Heetfeld A, et al. Allergic rhinitis to weed pollen in Germany: dominance by plantain, rising prevalence, and polysensitization rates over 20 years. Int Arch Allergy Immunol. 2020;181:128-135. doi:10.1159/000504297

10. Ronmark E, Warm K, Bjerg A, Backman H, Hedman L, Lundback B. High incidence and persistence of airborne allergen sensitization up to age 19 years. Allergy. 2017;72:723-730. doi:10.1111/all.13053

11. Siroux V, Ballardini N, Soler M, et al. The asthma-rhinitis multimorbidity is associated with $\operatorname{IgE}$ polysensitization in adolescents and adults. Allergy. 2018;73:1447-1458. doi:10.1111/all.13410

12. Zuberbier T, Bachert C, Bousquet PJ, et al. GA(2) LEN/EAACI pocket guide for allergen-specific immunotherapy for allergic rhinitis and asthma. Allergy. 2010;65:1525-1530. doi:10.1111/j.13989995.2010.02474.x

\section{Publish your work in this journal}

The Journal of Asthma and Allergy is an international, peer-reviewed open-access journal publishing original research, reports, editorials and commentaries on the following topics: Asthma; Pulmonary physiology; Asthma related clinical health; Clinical immunology and the immunological basis of disease; Pharmacological interventions and new therapies. The manuscript management system is completely online and includes a very quick and fair peer-review system, which is all easy to use. Visit http://www.dovepress.com/testimonials.php to read real quotes from published authors. 